\title{
Hurt Pounds: A Biopsychosocial-spiritual study
}

Sherri Harper Woods ${ }^{1 *}$, LISW-S, EMDR, Jeanine L. Mincher ${ }^{2}$, PhD, RDN, LD, Priscilla Njeri Gitimu ${ }^{3}$, PhD

${ }^{1 *}$ Assistant Professor, Department of Social Work, Youngstown State University, Cushwa Hall 3375, United States.

${ }^{2}$ Associate Professor Foods and Nutrition, Director of Coordinated Programs in Dietics, Chair Human Ecology, Youngstown State University, Department One University Plaza, Youngstown Ohio, United States.

${ }^{3}$ Associate Professor \& Coordinator - Merchandising: Fashion and Interiors Human Ecology, Department One University Plaza, Youngstown Ohio, United States.

Article Details
Article Type: Research Article
Received date: $16^{\text {th }}$ January, 2020
Accepted date: $07^{\text {th }}$ February, 2020
Published date: $08^{\text {th }}$ February, 2020
*Corresponding Author: Sherri Harper Woods, Assistant Professor, Department of Social Work, Youngstown State Univer-
sity, Cushwa Hall 3375, United States. E-mail: sdwoods02@ysu.edu
Citation: Woods, S.H. (2020). Hurt Pounds: A Biopsychosocial-spiritual study. J Ment Health Soc Behav 2(1):111. https://
doi.org/10.33790/jmhsb1100111
Copyright: $C 2020$, This is an open-access article distributed under the terms of the Creative Commons Attribution License
4.0, which permits unrestricted use, distribution, and reproduction in any medium, provided the original author and source are
credited.

\section{Abstracts}

Self-care in social work is acknowledged as a preventative, ethical and critical practice of holistic wellness. This article briefly introduces and reports the findings of 64 licensed social workers and counselors who participated in the Hurt Pounds: A Biopsychosocialspiritual study. The Hurt Pounds study examined the potential Biopsychosocial-Spiritual (BPSS) relationship between self-compassion, forgiveness, disordered eating, body image and body appreciation of licensed counselors and social workers as aspects of self-care. The article also introduces the theoretical framework on which the workshop was built and includes the practical applications of the BPSS model. The article concludes with guidelines for implementing the Hurt Pounds Self-care model workshop.

Key Words: Self-Care, Hurt Pounds, Biopsychosocial-spiritual, Forgiveness, Self-compassion, \& Disordered-eating

\section{Defining Hurt Pounds}

In Social Work the practice of self-care is understood as a way a person tends to their emotional, psychological, physical, and spiritual well-being, which becomes a foundation to maintaining health and wellness [1]. The practitioner not addressing their core holistic wellbeing can result in biological (disordered eating); psychological (self-compassion); social (body image and body appreciation); and spiritual (forgiveness) self-care risk factors and consequences. When these unaddressed risk factors and consequences manifest into neglect of self-care, when we do not engage in intentional self-care, when we treat self-care as an option instead of an occupational necessity, hurt pounds accumulate. Hurt pounds are defined as the weight that practitioners carry from unresolved hurts, habits, and hang-ups or the vicarious exposure to the unresolved hurts, habits, and hang-ups of others that contribute to the biological, psychological, social, and spiritual well-being of a practitioner.

\section{Theoretical Framework of the Integration of the 4Ps} in the Biopsychosocial-Spiritual Self-Care Model

In practice with social work learning outcomes, the Hurt Pounds continuing education workshop provided knowledge, skills, attitude, and application of self-care interventions for the practitioners to examine their Hurt Pounds. The Hurt Pounds multidimensional self-care training model includes the integration of the four Ps (predispositions, precipitants, perpetuates, and protective factors) in the Biopsychosocial model [2] and provides a holistic view of the biological, psychological, social, and spiritual pounds that manifest from unresolved hurts. This same Biopsychosocial-Spiritual and 4Ps was used to conceptualize the correlation between the biological (disordered eating); psychological (self-compassion); social (body image and body appreciation); and spiritual (forgiveness) predispositions, precipitants, perpetuates, and protective factors of social worker's self- care.

\section{The Biological Hurt Pounds and 4Ps of Self-Care Defining Biological Pounds Presenting Problem}

For the past twenty years, much of the public health focus has been on overweight and obesity and the importance of its prevention. The alarm was sounded when former Surgeon General David Satcher issued his call to action over the generation which may not live as long as their parents [3]. Compulsive overeating, which may lead to obesity is certainly a concern, however, there are other types of eating behaviors which can be problematic as well. There is a danger that the focus on overweight and obesity alone may overshadow other disordered eating behaviors that may also be occurring and that place individuals at risk.

\section{Definition of Pound and Use in relation to Health}

A pound of body weight is defined as being equivalent to 3,500 calories [4]. We measure weight in pounds or kilograms and define a healthy body weight as weight in pounds in relation to height in inches or centimeters [5]. Healthy weight is represented by a body mass index of 18.5 to 24.9. Falling above or below may indicate physical risk [5].

\section{Predisposing Factors \\ Disordered Eating}

Disordered eating can be defined as any type of abnormal eating pattern that cannot be defined using the DSM definitions of eating disorders (Anderson, 2015). This can include rigid eating rituals, preoccupation with food and even weight fluctuation, to name a few [6]. Disordered eating is not synonymous with Eating Disorders (ED) but may lead to a diagnosed Eating Disorder if left unchecked.

\section{Eating Disorders}

Eating Disorders are defined by specific criteria, generated by the DSM [7]. Eating disorders are not a choice that an individual makes [8], but rather a life-threatening condition which is influenced by biological factors. There are a variety of eating disorders or combinations of disorders that vary by symptom and cause.

\section{Precipitations of Disordered Eating}

Factors which lead to disordered eating can be categorized into 
three distinct areas: Biological, Psychological and Social. Each individual may be influenced by one or more of these factors in unique and different ways. $[9,10]$.

Biological factors include having a relative with either an eating disorder, a mental health issue, a dieting history or type I Diabetes Mellitus $[9,10]$. A combination of any of these may predispose an individual to risk. Psychological factors include a propensity towards perfectionism, body image concerns, a history of anxiety disorder or behavioral inflexibility with a focus on "rule following" $[9,10]$.

Social factors which may predispose one towards disordered eating behaviors include stigmas about weight, a history of being bullied, idealizing appearance, a history of trauma, and acculturation $[9,10]$. With the current social climate, including children who may be overscheduled, families who rarely take time to eat together and increased exposure to social media (which depicts unrealistic standards), the stage is set for disruptive and negative patterns of eating.

\section{Protective Factors}

Universal prevention is difficult, so spending time to target interventions is preferred [11]. Dismantling unrealistic standards is important. Particularly helpful, has been a project called The Body to learn to accept their bodies and embrace their differences [12].

Neumark-Sztainer et al. [13] also identify family meals as protective against Eating Disorders [14]. Being able to eat with others who know you intimately allows for cues of concern to be detected early in addition to providing a safe space to share stresses and problems.

\section{Predisposing Factors}

Family meals give the opportunity for decreasing the negative effects of social pounds. Family meals provide the opportunity for family members to give social support and validation and can possibly decrease the risk for an eating disorder [15].

\section{Precipitating Factors}

Many factors are barriers to frequent family meals. These include sociocultural influence, busy schedules, home environment, activities schedule, work schedule, location, psychosocial stress, unhealthy eating habits, low social support, poor relationships, food availability, and financial incapability [16]. The media and sociocultural influence also play a role in triggering social pounds. The more often people turn to the media, the more often their perception of themselves may worsen [15].

\section{Perpetuates \& Protective Factors}

Frequent family meals contribute to healthier habits amongst family members. Healthy home behaviors, such as eating habits can continue into adulthood [17]. Having the social support during family meals provides the stability and opportunity for validation towards concerning feelings and emotions.

\section{The Psychological Hurt Pounds and 4 Ps of Self-Care Presenting Problem}

An occupational hazard of the social work field includes the psychological pounds of vicarious trauma or secondary traumatic stress. Psychological symptoms of secondary traumatic stress that can be encountered by social workers and counselors as consequences of work-related stress. Psychological hurt pounds are decreased by understanding the predisposing, precipitants, perpetuating, and protective factors of these hurt pounds.

\section{Predispositions}

Self-compassion is defined as directing compassion inward [18]. The absence of self-compassion during adverse life experiences predisposes the social worker to psychological hurt pounds and decrease the compassion we have for ourselves thus decreasing the amount of empathy we have for our clients. Project whereby girls and young women are trained to question and not adopt a societal definition of body standards of "perfection" and

\section{Perpetuating Factors}

Psychological hurt pounds are perpetuated when we attempt to avoid pain. Self-compassion permits the experience of pain. Lack of self-compassion is a contributing factor to psychological hurt pounds.

\section{Precipitating and Perpetuating Factors}

In order to eliminate psychological hurt pounds, the examination of the unhealthy, hurtful, and habitual precipitating factors have to be examined. As caregivers the unhealthy mindsets of people pleasing, perfectionism, and performance perpetuate hurt pounds.

\section{Protective Factors}

When a social worker practices the psychological self-care of selfcompassion it serves as a protective factor of psychological hurt pounds by building empathy and shields us from the accumulation of unwanted psychological hurt pounds.

\section{The Social Hurt Pounds and 4 Ps of Self-Care Presenting Problem}

Body appreciation is associated with numerous and diverse indicators of well-being. A lack of body appreciation leads to social hurt pounds.

\section{Predispositions}

The extent to which an individual appreciates their own body is recognized as a proximal predictor of intuitive eating. Intuitive eating is broadly defined as eating in response to physiological hunger as opposed to emotions [19]. Intuitive eating predisposes individuals to social hurt pounds.

\section{Perpetuating Factors}

Body appreciation is an aspect of positive body image that is defined as the maintenance of a balanced, affectionate and healthconscious relationship with one's own body's features. Body appreciation exploration is crucial in intervention programs in the area of body image and eating disorders [20]. Poor body appreciation and a negative body image perpetuates social hurt pounds.

\section{Protective Factors}

There is a positive and strong association between body-appreciation with self-compassion. Self-compassion acts as a mediator between shame and body appreciation [20]. Greater body appreciation is enhanced by greater perceived body acceptance by others, selfcompassion, and non-appearance media consumption e.g. watching documentaries. These all serve as protective factors of social hurt pounds.

\section{The Spiritual Hurt Pounds and 4 Ps of Self-Care Presenting Problem}

It is the responsibility of the social work practitioner to establish a healing environment that is safe, secure, trustworthy, empathic, and non-judgmental. When a social worker is unable to resolve offenses of self and from others, the unresolved anger festers into a lack of forgiveness and the social worker accumulates spiritual hurt pounds. Predisposing Factor

The definition of self-forgiveness is letting go of the guilt and shame and giving up the need to dwell on what happened that made you feel that way [21]. Guilt and shame of self can reduce empathy for others. A reduction in empathy can be a symptom of burnout or compassion fatigue and is a predisposing factor of spiritual hurt pounds.

\section{Precipitating and Perpetuating Factors}

Like self-compassion, self-forgiveness is associated with psychological and relational well-being [22]. A lack of selfcompassion that embraces shame is a precipitant of self-forgiveness. Shame and guilt attached to psychological hurt pounds are triggers of spiritual hurt pounds. When social workers to not devote the selfcare to recognize and resolve wrongdoings with self-compassion, it perpetuates spiritual hurt pounds. 


\section{Protective Factors}

Social workers who addresses negative emotions with selfkindness and nonjudgment, work through the process of uncovering anger, deciding to forgive, working on forgiveness, and releasing the stronghold of the wrongdoing is building spiritual protective factors. Higher traits of self-compassion demonstrate less extreme reactions, less negative emotions, more accepting thoughts, and a greater tendency to put problems into perspective, while at the same time acknowledging responsibility [23].

\section{Methods}

\section{The Hurt Pounds Continuing Education Workshop and study}

The Hurt Pounds workshop was a three- hour, three part continuing education workshop offered to social workers and counselors. The workshop also explored whether unresolved hurts due to forgiveness issues relate to self-compassion, body image, body appreciation, and disordered eating. Hurt Pounds focused on how social workers and counselors engaged in intentional holistic (BiopsychosocialSpiritual) self-care. The biological segment was facilitated by a registered dietitian nutritionist/ licensed dietitian, and an associate professor of foods and nutrition. The psycho and spiritual segment was facilitated by an assistant professor of social work, licensed independent social worker, supervisor designation, and EMDR trained therapist. The social segment facilitated by an associate professor of Fashion.

Within the continuing education training, the participants were requested to complete a survey. The completion of the survey was voluntary and anonymous. Institutional human subjects approval was received before distribution of the survey.

The survey included a - 1) Demographic section which included frequency of sitting down/family at meals 2) Heartland Forgiveness Scale by [24]; 3) Self-Compassion by Raes et al. [25]; 4) EAT 26 by Gamer [26]; 5) Body Appreciation Scale-2 by Tylka [27]; and 6) Body Image Acceptance and Action Questionnaire by Sandoz et al. [28].

The remainder of the workshop focused on the proposed Hurt Pounds Self-care Training Model. The model is based on the theoretical framework of the Biopsychosocial four Ps model and offers the knowledge of a holistic approach to self-care, the skills to develop a holistic self-care plan, and the engagement in intentional application exercises that increase and sustain the social workers self-care protective factors.

\section{Results}

The total number of participants for the workshop was 64 social workers. The social workers were about $53 \%$ and the counselors about $34 \%$. The females were about $90 \%$ and most of the participants were Caucasian - $75 \%$. A complete description of participants' characteristics is available in Table 1.

Descriptive statistics of all the scales used in Hurt Pounds Survey was computed. Table 2 below details a sample item from each scale, the number of items, means, range, standard deviations and the reliability of each scale. All scales used in the survey exhibited strong or excellent internal consistency (see Table 2 for Cronbach's Alpha for all scales).

The data were analyzed to determine the interactions between the biological (disordered eating risk); psychological (self-compassion); social (body image- appreciation and acceptance); and spiritual (forgiveness) aspects of self-care.

\section{Biological aspects of self-care - measured by EAT 26 and sit down meals}

To measure the biological aspects self -care EAT 26 and responses on frequency of sit- down meals. EAT-26 was used to categorize the participants to be either at risk or not at risk of an eating disorder. Eat -26 has been used widely in inquiries as a dependable measure of identifying the presence of symptoms that are consistent with either a possible eating disorder or disordered eating behavior. Individuals who score 20 or greater (EAT-26 $\geq 20$ ) are considered to be at risk of having an eating disorder [26]. While used clinically, the EAT-26 is interpreted continuously, but in non-clinical samples like in the present study, it is fitting to dichotomize participants into at-risk and not at-risk for group comparisons [29, 30].

\begin{tabular}{|c|c|c|}
\hline & $\mathrm{N}$ & $\%$ \\
\hline Total number of participants $\mathrm{N}=64$ & 64 & $100 \%$ \\
\hline Females & 58 & $90.6 \%$ \\
\hline Males & 6 & $9.4 \%$ \\
\hline Social workers & 34 & $53.1 \%$ \\
\hline Counselors & 22 & $34.4 \%$ \\
\hline Both & 4 & $6.3 \%$ \\
\hline \multicolumn{3}{|l|}{ Marital status } \\
\hline Single 12 & 12 & $18.8 \%$ \\
\hline Married 40 & 40 & $62.5 \%$ \\
\hline Divorced 12 & 12 & $18.8 \%$ \\
\hline \multicolumn{3}{|l|}{ Ethnicity } \\
\hline African American & 12 & $18.8 \%$ \\
\hline Caucasian & 48 & $75.0 \%$ \\
\hline Hispanic/Latino & 3 & $4.7 \%$ \\
\hline Other & 1 & $1.6 \%$ \\
\hline \multicolumn{3}{|l|}{ Sit down at meal time } \\
\hline Seldom & 2 & $3.1 \%$ \\
\hline Sometimes & 12 & $19.8 \%$ \\
\hline Often & 20 & $31.3 \%$ \\
\hline Always & 30 & $46.9 \%$ \\
\hline Age & mean $=5.8$ & \\
\hline BMI (weight and height responses) & mean $=27.76$ & \\
\hline
\end{tabular}

Table 1 - Demographic characteristics and responses of the of the participants

Results indicated that $61(95.3 \%)$ of the participants were not at riskof getting an eating disorder and only $3(4.7 \%)$ were at-risk of getting an eating disorder. This result indicates that the participants were healthy in their eating habits. Additionally, the participants showed very good habits of often or always sitting down at meals (78.2\%).

\section{Forgiveness (Spiritual self -care) association to body image appreciation and acceptance (social self -care)}

The body image appreciation and body acceptance were each divided into two groups (above and below mean groups). Then an ANOVA (analysis of variance) was carried out to investigate the relationship between forgiveness and body image appreciation and acceptance. The forgiveness totals were used as the dependent variable while the body appreciation and acceptance (high and low groups) were each separately used as an independent variable.

Results indicated that the forgiveness mean $(m=101.88)$ for those with high body appreciation was significantly higher $(\mathrm{p}=0.001)$ than the forgiveness mean $(m=89.66)$ for those with low body appreciation. The results also indicated that the forgiveness mean $(m=100.18)$ for those with high body acceptance was significantly higher $(p=0.13)$ than the forgiveness mean $(m=90.7)$ for those with low body acceptance. (see table 3 for more details). 


\begin{tabular}{|c|c|c|c|c|c|c|}
\hline Name of Scale & Item Example & No. of items & Range & Mean & $\begin{array}{l}\text { Std. } \\
\text { Deviation }\end{array}$ & $\begin{array}{l}\text { Cronbach's } \\
\text { Alpha }\end{array}$ \\
\hline $\begin{array}{l}\text { Heartland Forgiveness } \\
\text { Scale }\end{array}$ & $\begin{array}{l}\text { 'I hold grudges against } \\
\text { myself for negative things } \\
\text { I've done.' }\end{array}$ & 18 & $59-126$ & 95.76 & 15.38 & 0.89 \\
\hline Self-Compassion Scale & $\begin{array}{l}\text { 'I try to be understanding } \\
\text { and patient towards those } \\
\text { aspects of my personality I } \\
\text { don't like.' }\end{array}$ & 12 & $19-58$ & 42.88 & 8.73 & 0.83 \\
\hline EAT 26 & $\begin{array}{l}\text { 'Am terrified about being } \\
\text { overweight.' }\end{array}$ & 26 & $0-28$ & 6.22 & 28 & 0.79 \\
\hline $\begin{array}{l}\text { Body Appreciation } \\
\text { Scale-2 }\end{array}$ & 'I respect my body. ' & 10 & $10-50$ & 36.75 & 8.03 & 0.94 \\
\hline $\begin{array}{l}\text { Body Image } \\
\text { Acceptance and Action } \\
\text { Questionnaire }\end{array}$ & $\begin{array}{l}\text { 'There are many things I } \\
\text { do to try and stop feeling } \\
\text { bad about my body weight } \\
\text { and shape.' }\end{array}$ & 29 & $85-202$ & 151.81 & 28.5 & 0.93 \\
\hline
\end{tabular}

\begin{tabular}{|l|l|l|l|l|l|l|}
\hline & $\mathrm{N}$ & Forgiveness Mean & Std. Deviation & Mean Square & F & Sig \\
\hline High Body Appreciation( $>$ mean $)$ & 32 & 101.88 & 13.99 & 202.105 & 11.82 & .001 \\
\hline Low Body Appreciation $(<$ mean & 32 & 89.66 & 14.43 & 2388.77 & & \\
\hline & & & & & & \\
\hline $\begin{array}{l}\text { High Body image acceptance } \\
(>\text { mean })\end{array}$ & 34 & 100.18 & 14.32 & 1411.18 & 6.48 & .013 \\
\hline Low Body Appreciation $(<$ mean $)$ & 30 & 90.7 & 15.25 & 217.88 & & \\
\hline
\end{tabular}

Table 3 - ANOVA of Forgiveness Total by Body appreciation and body image acceptance

Self- Compassion (Psychological self -care) association to body image appreciation and acceptance (social self -care)

ANOVA (analysis of variance) was carried out to investigate the relationship between self-compassion and body image appreciation and acceptance. The self-compassion totals were used as the dependent variable while the body appreciation and acceptance (high and low groups) were each separately used as an independent variable.
Results indicated that the self-compassion mean $(m=46.10)$ for those with high body appreciation was significantly higher ( $p$ $=0.003)$ than the self-compassion mean $(\mathrm{m}=39.66)$ for those with low body appreciation. It also indicated that the self-compassion mean $(m=45.94)$ for those with high body acceptance was significantly higher $(\mathrm{p}=0.002)$ than the self-compassion mean $(\mathrm{m}=39.40)$ for those with low body acceptance. (see table 4 for more details)

\begin{tabular}{|l|l|l|l|l|l|l|}
\hline & $\mathrm{N}$ & Self-compassion Mean & Std. Deviation & Mean Square & F & Sig \\
\hline High Body Appreciation $>$ mean $)$ & 32 & 46.10 & 8.09763 & 663.06 & 9.93 & .003 \\
\hline Low Body Appreciation(<mean) & 32 & 39.66 & 8.25 & 66.81 & & \\
\hline & & & & & & \\
\hline $\begin{array}{l}\text { High Body image acceptance } \\
(>\text { mean })\end{array}$ & 34 & 45.94 & 7.55 & 681.92 & 10.25 & .002 \\
\hline Low Body Apperception $(<$ mean $)$ & 30 & 39.40 & 8.79 & 66.50 & & \\
\hline
\end{tabular}

$* \mathrm{p}=0.5$. Table $4-$ ANOVA of Self Compassion Total by body appreciation and body image acceptance

\section{Discussion and Conclusion}

Participants demonstrated good eating habits, forgiveness, and self-compassion and few participants were at risk for acquiring an eating disorder. The results also showed that the participants were demonstrating Biopsychosocial-Spiritual self-care, inferring that when social workers intentionally engage in holistic self-care, they sustain holistic well-being.

Results also indicate that the social workers and counselors took care of themselves in regards to this aspect of their eating habits. However, the average BMI (see table 1) for the participants was 27.7 which falls outside of the healthy weight range recommendations, indicating there may be some element of hurt pounds. It should be noted, however, that there are cultural norms in operation which may work against health recommendations regarding weight. Many cultures may prefer larger or smaller body types, and therefore may provide a barrier to the achievement of healthy body weight.

The forgiveness mean for those with high body appreciation and acceptance was higher than the forgiveness mean for those with low body appreciation and acceptance. About half of the participants had high forgiveness means which was connected with enhanced body appreciation and body acceptance. Consequently, social workers and counselors ought to include forgiveness of others and self as one important piece of spiritual self-care. A total of 55 to 89 on the Total HFS indicates that one is about as likely to forgive, while a score of 
90 to 126 on the Total HFS indicates that one is usually forgiving of oneself, others, and uncontrollable situations [24].

According to Marta-Simões et al, [20], self-compassion acts as a mediator between shame and body appreciation. In this study, the self-compassion mean for those with high body appreciation and acceptance was higher than the self-compassion mean for those with low body appreciation and acceptance. Notably, about half of the participants had high self-compassion means which was associated with better body appreciation and body acceptance. Consequently, social workers and counselors ought to include self-compassion as an essential piece of their psychological self-care.

\section{Future Implications of the Study}

An NASW editorial reminds us that self-care is a preventative method that must be intentional and that caring for ourselves must be routine and viewed as a necessary part of doing the important work we get to do that we can be optimal for those who rely on us [31]. Even with an editorial reminder that self-care is an ethical imperative, we still lack evidence-based strategies to increase and sustain our Biopsychosocial-Spiritual well-being. As we seek to avoid the occupational hazards of our field and to care for the hurts of others, it is necessary that we implement holistic practices to care for ourselves.

Conflict of interest: The author has declare no conflict of interest.

\section{References}

1. Monk, L. (2011). Self-care for social workers: a precious commodity, and ethical imperative. Perspective 33 (1): 407.

2. Ashford, J.B., LeCroy,L., \& Williams, L. (2018). Human behavior in the social environment. Boston, MA: Cengage Learning.

3. U.S. Department of Health and Human Services: Surgeon General's Report: The Surgeon General's Call to Action to Prevent and Decrease Overweight and Obesity, (2001).

4. Office of Disease Prevention and Health Promotion. Definition of one pound.

5. Centers for Disease Control and Prevention. What is BMI.

6. Anderson, M. (Feb 21, 2015). What is Disordered Eating? Academy of Nutrition and Dietetics.

7. American Psychiatry Association DSM 5:

8. National Institutes of Health: National Institutes of Mental Health. Eating Disorders: About More than Food.

9. National Eating Disorders Association (NEDA) (2018). What are Eating Disorders?

10. National Eating Disorders Association (NEDA) - Risk Factors.

11. National Eating Disorders Association (NEDA) -Prevention.

12. National Eating Disorders Association (NEDA) - The Body Project.

13. Neumark-Sztainer, D., Larson, N., Fulkerson, J. A., Eisenberg, M. E., \& Story, M. (2010). Family Meals and Adolescents: What Have We Learned From Project EAT (Eating Among Teens) [Abstract]. Public Health Nutrition,13(7),1113-1121.

14. Neumark-Szainer, D., Wall, M, Story, M, Sherwood, ME. (2009). Five year longitudinal predictive factors for disordered eating in a population-based sample of overweight adolescents: implications for prevention and treatment. International Journal of Eating Disorders, 42, 664-672.

15. Sanchez-Carracedo, D., Carretero, C., \& Conesa, A. (2017). Roundtable on the Prevention of Eating Disorders: The Catalan Public Policy Initiative [Abstract]. Eating Behaviors ,25, 15-17.

16. Skeer, M., \& Ballard, E. (2013). Are Family Meals as Good for Youth as We Think They Are? A Review of the Literature on Family Meals as They Pertain to Adolescent Risk Prevention [Abstract]. Journal of Youth \& Adolescence ,42(7), 943-963.
17. Lytle , L. (2017). How to Create A Healthy Home Food Environment [Abstract]. Annals of Nutrition \& Metabolism,71, 1338-1339.

18. Neff, K. \& Knox, M. (2017). Self-compassion. Encyclopedia of Personality and Individual Differences. New York: Springer International Publishing.

19. Oswald, A., Chapman, J., \& Wilson, C. (2017). Do interoceptive awareness and interoceptive responsiveness mediate the relationship between body appreciation and intuitive eating in young women?. Appetite, 10966-72. doi:10.1016/j. appet.2016.11.019.

20. Marta-Simões, J., Ferreira, C., \& Mendes, A. L. (2016). Exploring the effect of external shame on body appreciation among Portuguese young adults: The role of self-compassion. Eating Behaviors, 23174-179. doi:10.1016/j.eatbeh.2016.10.006.

21. Tipping, C. (2011). Radical self-forgiveness. .Boulder, CO: Sounds True Inc.

22. Cornish, M.A., Wade, N.G. (2015). Journal of Counseling and Development 93, 96-104.

23. Neff, K. D. \& Germer, C. (2017). Self-compassion and psychological well-being. In J. Doty (Ed.) Oxford Handbook of Compassion Science, Chap. 27. Oxford University Press.

24. Thompson, L. Y., \& Synder, C. R. (2003). Measuring forgiveness. In Shane J. Lopez \& C. R. Snyder (Eds.), Positive psychological assessment: A handbook of models and measures (pp. 301 312). Washington, DC, US: American Psychological Association.

25. Raes, F., Pommier, E., Neff, K. D., \& Van Gucht, D. (2011). Construction and factorial validation of a short form of the SelfCompassion Scale. Clinical Psychology \& Psychotherapy. 18, 250-255.

26. Garneretal.1982,PsychologicalMedicine,12,(871-878).EAT-26.

27. Tylka, T. L. (2012). Positive psychology perspectives on body image. In T. F.Cash (Ed.), Encyclopedia of body image and human appearance (Vol. 2) (pp.657-663). Oxford, England: Academic Press. http://dx.doi.org/10.1016/B978-0-12-3849250.00104-8.

28. Sandoz, E. K. \& Wilson, K. G. (2006). Assessing Body Image Acceptance. Unpublished Manuscript. University of Mississippi.

29. Anstine, D., \& Grinenko, D. (2000). Rapid screening for disordered eating in college-aged females in the primary care setting. J Adolesc Health. 2000 May;26(5):338-42. DOI: 10.1016/s1054-139x(99)00120-2.

30. Jones, J.M., Bennett, S., Olmsted, M.P., Lawson, M.L., \& Rodin, G. (2001). Disordered eating attitudes and behaviours in teenaged girls: a school-based study. CMAJ. 2001 Sep 4;165(5):547-52.

31. Bent-Goodley, T. B. (2017). Being intentional about self-care for Social Workers. Social Work, 63(1), 5-6. 